\title{
Case Reports of an Innovative Technique for Columellar Reconstruction in Children Using a Custom-Made Composite Graft from the Back of the Ear
}

\author{
ELSONBATY M.A., M.D. and MOHAMED ABD-ELRAHIM, M.D. \\ The Department of Plastic and Reconstructive Surgery, Assiut University Hospital, Egypt
}

\begin{abstract}
The columella is unique as a nasal subunit. The nasal columella has traditionally been a difficult subunit to repair because of its unique contours, tenuous vascularity, and limited availability of adjacent skin. Columellar defects can significantly impair aesthetic appearance. Columellar damage can be caused by congenital loss, ischemic injuries, trauma, tumor resection, and vascular malformations. Columella reconstruction can be very challenging for plastic surgeons.
\end{abstract}

Defects of the nasal columella can be repaired using various methods including composite free grafts from the ear $(1,2)$, nasolabial flaps (3), nasofacial sulcus flaps (4), forehead flaps (5), extended Abbe flaps (6), and free flaps (7).

Auricular chondrocutaneous composite grafts have been reported in the literature. The main advantage of these grafts are avoidance of facial scars and provision of tip support. However, risk of composite graft loss was reported as a main complication.

Herein, we report two cases of columellar defect reconstructions in children using a custom-made columella from a conchal composite graft with the tongue-in-groove principle. The main advantages of this technique are that it is a onestage method; the custom-made columella depends on the dimensions of the defect, so it can be tailored according to the dimension of the columellar defect; the use of the tonguein-groove principle increases the contact surface between the graft and recipient, therefore, increase the possibility of survival of the reconstructed columella; with minimal donor site morbidity.

Key Words: Columellar reconstruction - Auricular cartilage - Composite graft.

\section{INTRODUCTION}

The columella is a unique nasal subunit, and defects in the columella can significantly impair aesthetic appearance. The columella determines the projection of the nasal tip, defines the nasolabial angle, and influences the relationship between the nasal base and alar rims. The columella is divided into three segments of equal length: The anterior lobular portion, the intermediate narrowest portion, and the basal portion [8]. Columellar damage can develop because of a wide variety of causes, including congenital loss, ischemic injuries, trauma, tumor resection, and vascular malformations.

Columella reconstruction can be very challenging for plastic surgeons. Defects of the nasal columella can be repaired using various methods, including composite free grafts from the ear [1,2], nasolabial flaps [3], nasofacial sulcus flaps [4], forehead flaps [5], extended Abbe flaps [6], and free flaps [7]. A composite graft from the ear for nasal reconstruction was first described by Konig in 1902 [9]. A composite graft goes through four phases of color changes after successful reconstruction surgery: Phase I, the cut graft will appear dead white immediately after surgery; Phase II, $6 \mathrm{~h}$ after surgery, the graft will turn pale pink; Phase III, within 12 to $24 \mathrm{~h}$ postoperatively, the color of the graft will turn deep cyanosis; and Phase IV, 3 to 6 days postoperatively, the graft will acquire a healthy color [9]. The composite graft goes through three phases of vascularization. In the imbibition phase, the graft absorbs nutrients from the underlying recipient bed during the initial 2-3 days after surgery. In the inosculation phase, which occurs within 4-6 days after surgery, blood vessels in the graft grow to meet the blood vessels in the recipient bed. In the neovascularization phase, new blood vessels form, bridging the graft to the recipient bed at days 6-7 after surgery [10].

In this report, we describe two cases of columellar defect reconstructions in children using a custom-made columella from a conchal composite graft and the tongue-in-groove principle. Previous reports recommend a maximum diameter of $10 \mathrm{~mm}$ for chondrocutaneous grafts [11]. However, good results have been reported with grafts up to $10 \mathrm{x}$ 
$18 \mathrm{~mm}$ [12]. Ideally, the center of the graft should be no more than $5 \mathrm{~mm}$ from the blood supply [13]. The main advantage of a custom-made columella from a conchal composite graft is that the surgery can be performed in a single stage with an en bloc graft formed of two or three layers of tissue [9]. Complications that can arise after extraction of the graft include asymmetry, contracture, ear deformity, and hypertrophic scarring [12].

\section{CASE REPORTS}

The first case was a 13-year-old girl with almost total columellar damage secondary to pressure necrosis from the prolonged application of a Ryle's tube at a young age. The patient underwent two previous failed columellar reconstructions by other plastic surgeons 1 year apart using helical root chondrocutaneous composite grafts from both ears at the ages of 9 and 10 years (Fig. 1).

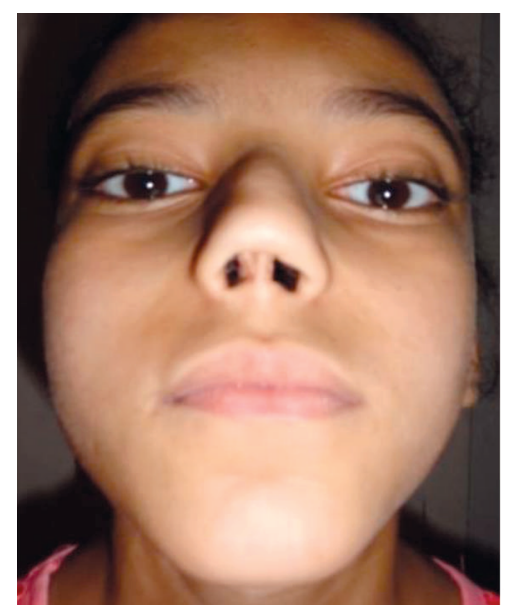

(A)

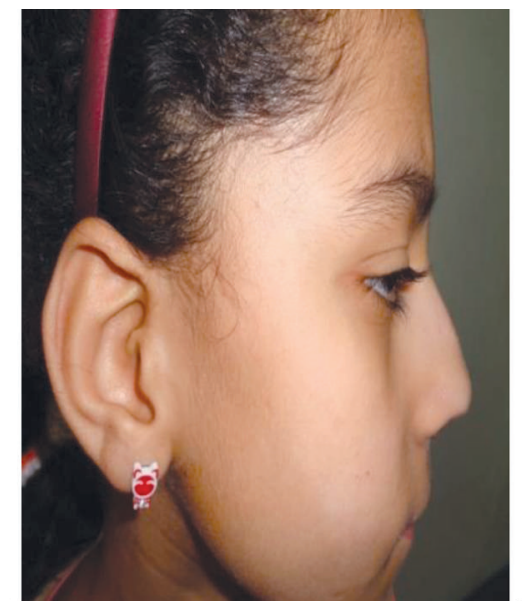

(B)

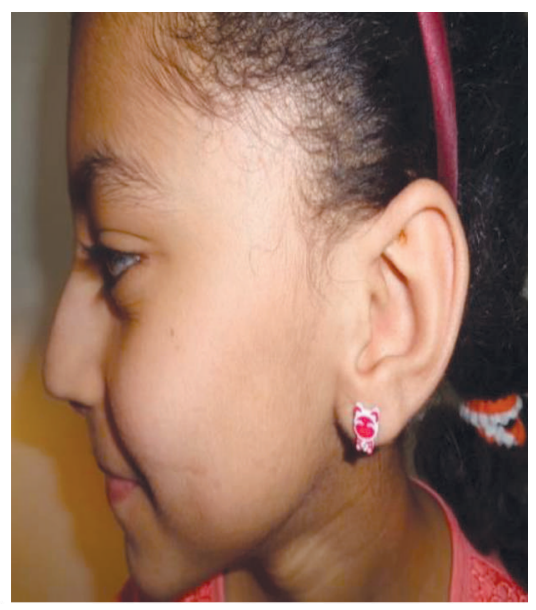

(C)

Fig. (1): (A) A 13 year old girl with columellar damage, $(B, C)$ The defects in the root of the helix in both ears after taking the composite grafts.

For this patient, a custom-made columella harvested from the posterior aspect of the ear was performed. The dimensions of the columellar defect were measured, including the length, width, and depth of the defect. The desired design for the removal of the composite graft was marked. Under general anesthesia, the posterior surface of the ear was infiltrated with solution consisting of $1 \%$ lidocaine and 1:200,000 epinephrine. The anterior surface of the ear was also infiltrated to facilitate the dissection of the conchal cartilage from the overlying skin. In this design, an ellipse
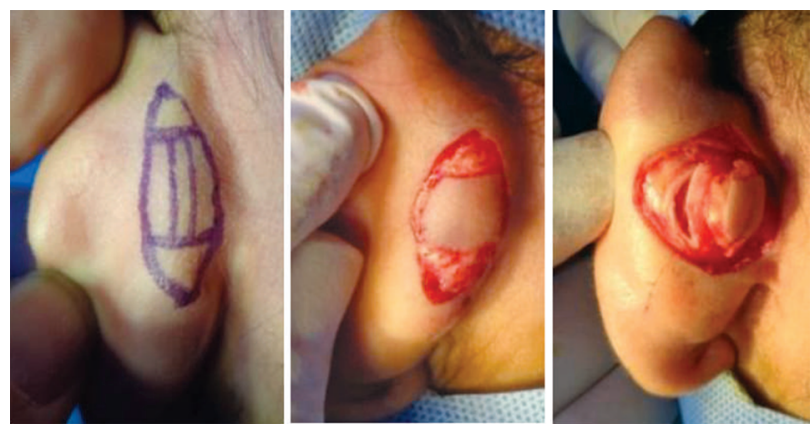

Fig. (2): The steps of removal of the composite graft from the posterior surface of the ear. about $20 \mathrm{~mm}$ in length and $12 \mathrm{~mm}$ in width (central part) was made in the skin, followed by deepithelization of the upper and lower poles of the ellipse leaving the intermediate $10 \mathrm{~mm}$. The next step was the dissection of the conchal cartilage from the overlying anterior ear skin. Then, an ellipse of the conchal cartilage about $16 \mathrm{x} 4 \mathrm{~mm}$ was incised before the removal of the composite graft (Fig. 2). The custom-made columellar graft was sutured after insertion of the superior and inferior de-epithelized tissues in the prepared pocket (Fig. 3).
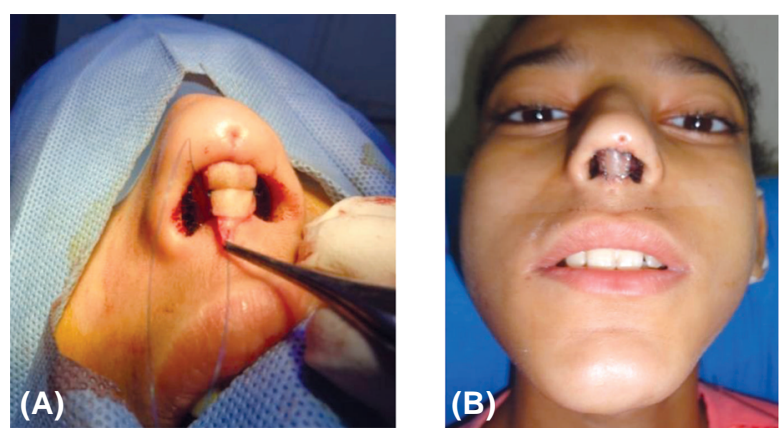

Fig. (3): The custom-made columellar graft was sutured after insertion of the superior and inferior de-epithelized tissues in the prepared pocket. 
The graft underwent color changes as shown in Fig. (4). Twenty-four hours after surgery, the graft appeared white. The graft appeared cyanotic $72 \mathrm{~h}$ after surgery and developed a healthy color by 3 weeks after surgery.

The columella, which was custom-made from the posterior aspect of the ear, was functionally and aesthetically successful with no change in size at the 3-month follow-up with very minimal donor site morbidity, in the form of a short linear scar in the back of the concha (Figs. 5,6).

The second case was a 14-month-old female infant with damage of the columella secondary to pressure necrosis from nasal continuous positive airway pressure during 30 days in the neonatal ICU. (Fig. 7).
(A)

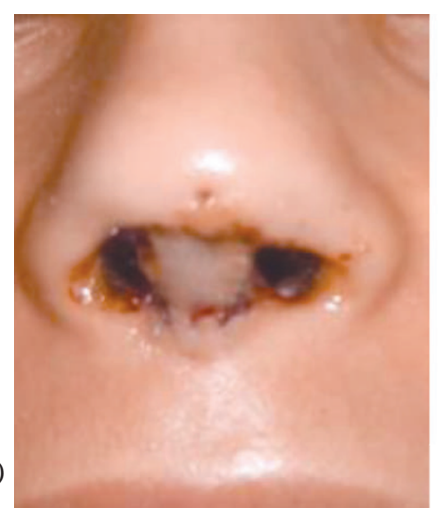

(B)



(C)

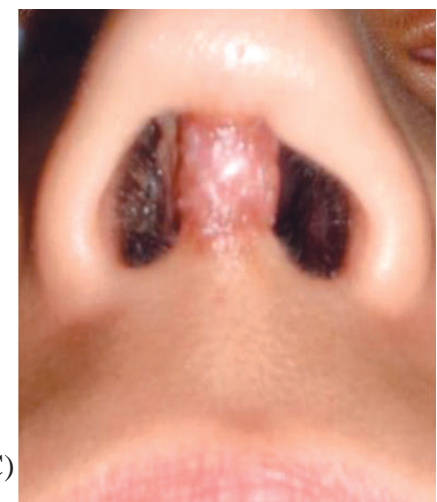

Fig. (4): The color changes of the composite graft, (A) 24 hours post op., (B) 72 hours post op. and (C) 3 weeks post op.

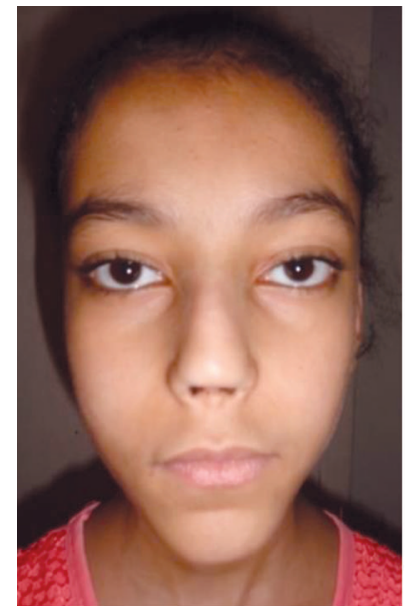

(A)

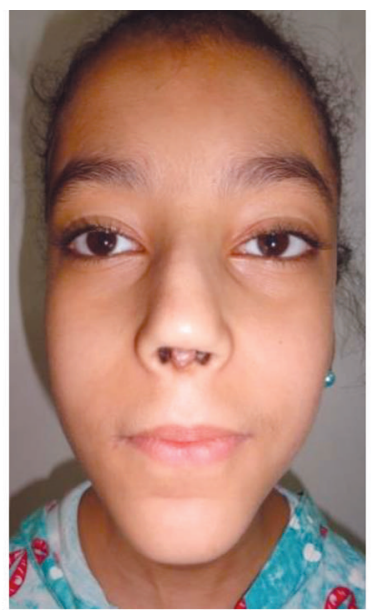

(B)

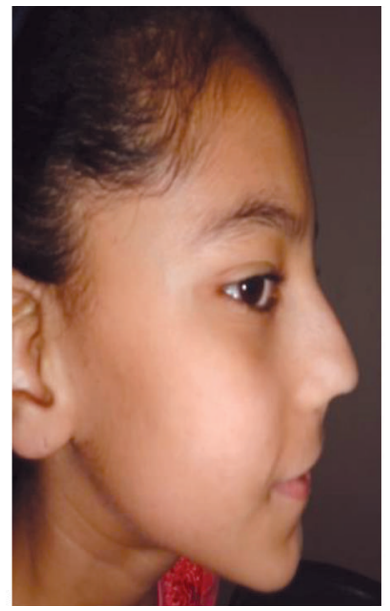

(C)

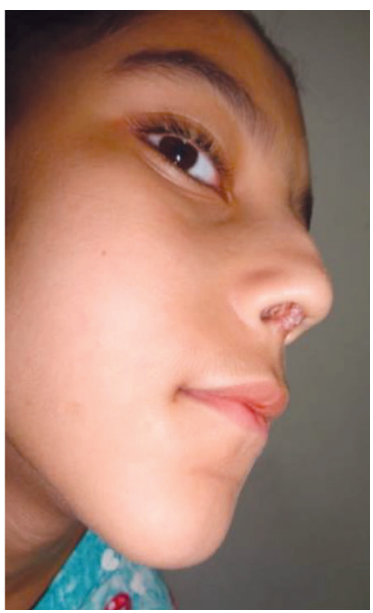

(D)

Fig. (5): (A,C) Preoperative frontal and lateral views. (B,D) Postoperative frontal and oblique views.


Fig. (6): The anterior and posterior aspects of the left ear, showing minimal morbidity in the form of postauricular linear scar. 

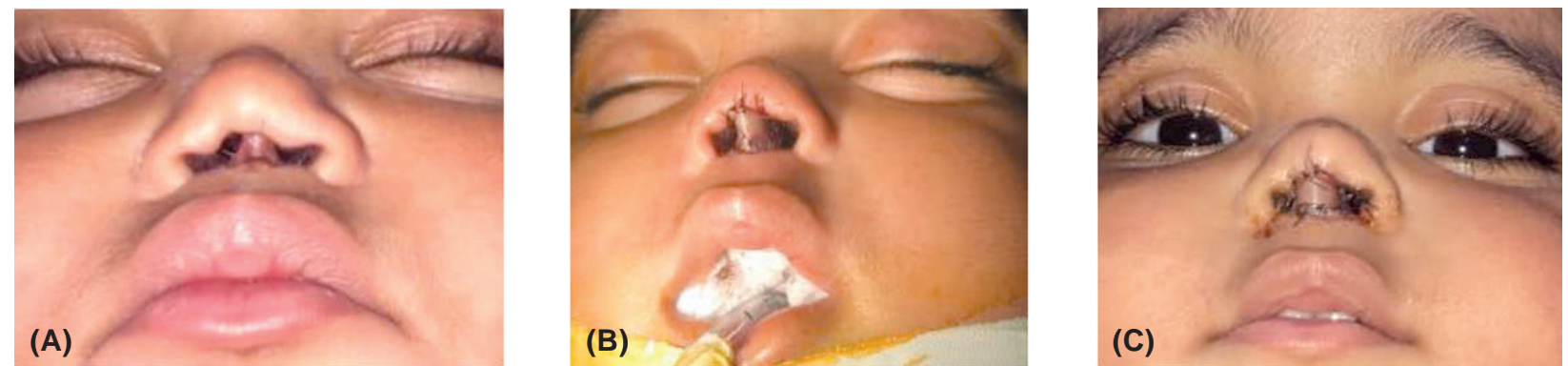

Fig. (7): (A) A 14-month-old female infant with loss of the columella, (B) Intra-op, immediately after columellar reconstruction using the custom made retro auricular composite graft, (C) 12 hours post op.
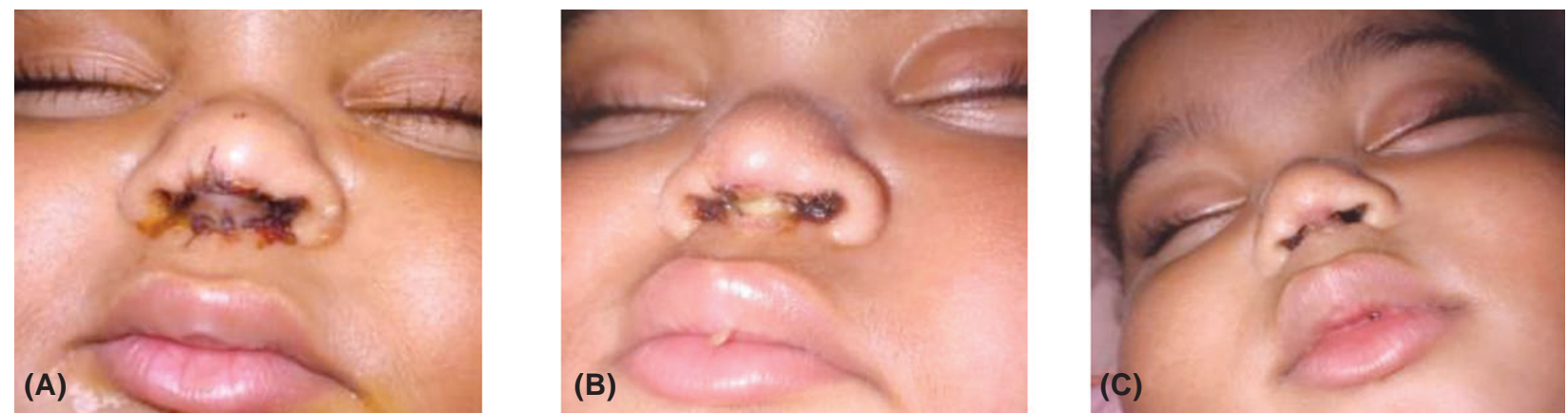

Fig. (8): (A) 48 hours post op., (B) One week post op., (C) One month post op.

\section{DISCUSSION}

The columella is the nasal subunit that provides support and projection of the nasal tip. One of the most common causes of columellar loss is nasal trauma due to nasal continuous positive airway pressure in newborns $[\mathbf{1 4 , 1 5}$. The absence of a columella results in marked functional and aesthetic defects and requires reconstructive surgery.

The ideal reconstructive technique should consider the three dimensions of the defect, provide nasal tip projection, matched color and texture, and minimal donor site morbidity. Composite grafts [1,2] and several flaps, including nasolabial [3], nasofacial sulcus [4], and forehead flaps [5], are useful in repairing defects of the nasal columella. All these techniques can be used in adults and elderly patients with little defects in cosmetic appearance because of the laxity of the tissues and good scar appearance in elderly patients in comparison to children. However, these reconstructive techniques do not work well in children. For columellar reconstruction in children, we try to avoid the use of flaps because of the tight skin and the high possibility of donor site morbidity. Furthermore, flap incisions are particularly difficult to conceal in children $[\mathbf{1 6 , 1 7 ]}$.

In this report, we present an innovative technique for columellar reconstruction in children using a custom-made graft from the posterior aspect of the ear. We remove an ellipse of tissue from the posterior surface of the ear, according to the dimensions of the columellar defect. This ellipse consists of skin, underlying soft tissue, and an attached smaller ellipse of conchal cartilage. From this composite graft, we customize the shape of the columellar defect and adding two triangular dermal flaps using a tongue-in-groove technique to increase the surface contact to the recipient site.

Composite grafts can be harvested from many sites of the ear in relation to the helix. The ear provides a good donor site with minimal donor site morbidity, but sometimes, it is inadequate for structural reconstruction and does not fit the shape needed for reconstruction. Publications by Joseph [18] and Limberg [19] describing high failure rates discouraged many surgeons until successful reports $[20,21]$ established the procedure. For these reasons, we resort to the use of the custom-made composite graft with the tongue-in-groove principle to improve survival rates, provide adequate tissue for the desired columellar reconstruction, and minimize the donor site morbidity.

\section{Conclusion:}

We present a safe and versatile technique for columellar reconstruction using a one-stage operation. This technique provides very satisfactory aesthetic results regarding color and texture matching with minimal patient morbidity. 


\section{REFERENCES}

1- Lewin M.L.: Congenital absence of the nasal columella. Cleft Palate J., 25: 58-63, 1988.

2- Teltzrow T., Arens A. and Schwipper V.: One-stage reconstruction of nasal defects: Evaluation of the use of modified auricular composite grafts. Facial Plast. Surg., 27: 2438, 2011.

3- Nicolai J.P.: Reconstruction of the columella with nasolabial flaps. Head Neck Surg., 4: 374-9, 1982.

4- Jayarajan R.: Total columella reconstruction using nasocheek flap and septal cartilage graft. Plast. Reconstr. Surg. Glob Open, 3: e559, 2015.

5- Menick F.J.: Aesthetic refinements in use of forehead for nasal reconstruction: The paramedian forehead flap. Clin. Plast. Surg., 17607-622, 1990.

6- Zapater E., Simon E., Ferrandis E. and Vendrell J.B.: Reconstruction of upper lip, columella and premaxilla with an extended Abbe flap: Report of a case. Auris Nasus Larynx, 29: 305-308, 2002.

7- Benito-Ruiz J., Raigosa M. and Yoon T.S.: Columella reconstruction using a free flap from the first web space of the foot. Ann. Plast. Surg., 69: 279-82, 2012.

8- Vanessa S. and Frank A.: Surgical Options in Columellar Reconstruction, Otolaryngology - head and neck surgery, Volume 120 Number 6, 1999.

9- Konig F., ZurDeckung von Defekten der Nasenfugel and Klin Wochenschr, 7: 137-8, 1902. Quoted by Symonds F.C., Crikelair G.F. Auricular composite grafts in nasal reconstruction: A report of 36 cases. Plast. Reconstr. Surg., 37: 433-7, 1966.

10- Joseph J. Leipzig: Curt Kabitzsch; 1931. Nasenplastik; p. 383. Quoted by McLaughlin CR Composite ear grafts and their blood supply. Br. J. Plast. Surg., 7: 274-8, 1954.

11- Haas A.F. and Glogau R.G.: A variation of composite grafting for reconstruction of full-thickness nasal alar defects. Arch. Dermatol., 130: 978-80, 1994.
12- Son D., Kwak M., Yun S., Yeo H., Kim J. and Han K.: Large auricular chondrocutaneous composite graft for nasal alar and columellar reconstruction. Arch. Plast. Surg., 39: 323-8, 2012.

13- Burget G.C.: Aesthetic reconstruction of the nose. In: Mathes SJ, editor. Plastic Surgery. The Head and Neck. $2^{\text {nd }}$ ed. Vol. 2. Philadelphia: Elsevier, pp. 573-648, 2006.

14- Shanmugananda K. and Rawal J.: Nasal trauma due to nasal continuous positive airway pressure in newborns. BMJ Journal January - Volume 92 - 1, 2007.

15- Ozan Gökdoğan1, M.D. and Fikret leri2, M.D.: Nasal Complications Related with Cpap Treatment, ENT Updates, 8 (3): 133-138, 2018.

16- Sherris D.A., Fuerstenberg J., Danahey D. and Hilger P.A.: Reconstruction of the nasal columella. Arch. Facial Plast. Surg., 4: 42-46, 2002.

17- Inchingolo F., Abenavoli F.M., De Angelis F., Orefici A., Santacroce L. and Dipalma G.: Conservative surgical approach to restore necrotic columella in patients undergoing neonatal usage of nasogastric tube. Ann. Maxillofac. Surg., 7: 89-91, 2017.

18- Joseph J. Leipzig: Curt Kabitzsch; 1931. Nasenplastik; p. 383. Quoted by McLaughlin CR Composite ear grafts and their blood supply. Br. J. Plast. Surg., 7: 274-8, 1954.

19- Limberg A.A.: Rhinoplasty using free transplant from concha. Sov Khir., 9: 70, 1935. Quoted by Symonds F.C., Crikelair G.F. Auricular composite grafts in nasal reconstruction: A report of 36 cases Plast. Reconstr. Surg., 37: 433-7, 1966.

20- McLaughlin C.R.: Composite ear grafts and their blood supply. Br. J. Plast. Surg., 7: 274-8, 1954. Meade RJ.

21- Composite ear grafts for construction of columella; composite ear grafts for the correction of nasal deformities associated with cleft lip and other congenital and posttraumatic deficiencies of the columella. Plast. Reconstr. Surg. Transplant Bull, 23: 134-47, 1959. 